\section{Estudo \\ CoDebate}

em Testã⿻

Planejamento
Revista Estudo \& Debate, Lajeado, v. 28, n. 4, 2021. ISSN 1983-036X

DOI: http://dx.doi.org/10.22410/issn.1983-036X.v28i4a2021.2834

\title{
MERCADO INTERNO (NACIONAL) E EXTERNO (EXPORTADOR): AS EMPRESAS TÊM COERÊNCIA NO DISCURSO EM SUAS ATITUDES “DITAS SUSTENTÁVEIS”?
}

\author{
Thiago Santi ${ }^{1}$, Denize Demarche Minatti Ferreira ${ }^{2}$, Janaína da Silva Ferreira ${ }^{3}$
}

\begin{abstract}
Resumo: A extraçáo de recursos naturais e o tratamento dado a eles causam prejuízos ambientais e, consequentemente, afetam o modo de vida das pessoas. Dessa forma, este estudo analisa a coerência do discurso das 28 empresas listadas no Índice de Sustentabilidade Empresarial da Brasil, Bolsa, Balcáo (ISE B3). A metodologia segrega a amostra em dois grupos: as que exportam e as que comercializam no mercado interno e aplica a análise de conteúdo (BARDIN, 2011) no discurso das empresas e nas açóes que declaram ser "sustentáveis". Os achados evidenciaram que as empresas parecem transparecer serem sustentáveis e coerentes, além do que as exportadoras possuem mais coerência em suas respostas, pela declaração de iniciativas, como projetos sociais para a comunidade, além de medidas de controle e de conscientizaçáo para que utilizem recursos naturais de forma racional. Ainda, os resultados contribuem para que os stakeholders tenham melhor visão da coerência do discurso das empresas com as quais possuem ligação, além de saberem quais são as preocupações das mesmas com a sustentabilidade, seja para investidores, que buscam empresas comprometidas, clientes, para que saibam os impactos dos produtos consumidos e serviços prestados, além de outros diferentes públicos que se relacionam com as empresas.
\end{abstract}

Palavras-chave: ISE; Sustentabilidade; Medidas sustentáveis.

\section{INTERNAL MARKET (DOMESTIC) AND EXTERNAL (EXPORTER): DO THE COMPANIES PRESENT CONSISTENCY BETWEEN THEIR SPEECH AND THEIR “SO CALLED SUSTAINABLE” ATTITUDES?}

\begin{abstract}
The extraction and handling of natural resources cause environmental damage and, consequently, affect people's way of life. Thus, this study examines the coherence of the discourse of 28 companies listed on the Corporate Sustainability Index of Brazil, Bolsa, Balcão (ISE B3). Our methodology segregates the sample into two groups: exporters and domestic traders, and uses content analysis (BARDIN, 2011) on the companies'
\end{abstract}

1 Acadêmico de Ciências Contábeis da Universidade Federal de Santa Catarina (UFSC)

2 Contadora, Bióloga. Doutora em Engenharia e Gestão do Conhecimento pela Universidade Federal de Santa Catarina (UFSC). Professora do Departamento de Ciências Contábeis da UFSC.

3 Contadora. Doutoranda do Programa de Pós-graduação em Contabilidade pela Universidade Federal de Santa Catarina UFSC. 
discourse and on the actions they state as "sustainable". Findings revealed that companies appear to be sustainable and coherent, and that exporters show more coherence in their answers, by declaring initiatives such as social projects for the community, as well as control and awareness measures for the rational use of natural resources. Furthermore, results contribute to a better understanding of the stakeholders on the coherence of the discourse of the companies with which they relate, as well as their concerns with sustainability, be it for investors, who seek committed companies, customers, who need to be aware of the impacts of the consumed goods and rendered services, or for other different publics who relate to the companies.

Keywords: ISE; Sustainability; Sustainable measures.

\section{INTRODUÇÁO}

Após o período pós-guerra foi crescente o desgaste do meio natural, motivado principalmente pela industrializaçáo acelerada, criando necessidade de controlar a utilizaçáo dos recursos ambientais (MOLINA, 2019). Durante a Conferência das Naçôes Unidas sobre o Ambiente Humano, em Estocolmo, na Suécia, no ano de 1972, iniciou a discussão sobre desenvolvimento sustentável (KATO, 2008), porém, o conceito teve visibilidade após 1987 e ficou conhecido como aquele que náo esgote os recursos, náo comprometendo assim as próximas geraçôes (COLARES et al., 2012).

Milani Filho (2008) pontua que a partir do início do século XXI, as empresas começaram a informar a adoçáo de práticas sustentáveis que atendam aos interesses de seus stakeholders que se importam com a causa social e ambiental, assim as empresas melhoram sua imagem e influenciam as decisóes de consumidores, o que é uma vantagem competitiva (ROCHA et al., 2019; DIAS; HENKES; ROSSATO, 2020). Uma das formas de destacar as empresas com perfil sustentável para o mercado de capitais é inseri-las na carteira do ISE B3 que harmoniza investimentos com desenvolvimento sustentável demandado pela sociedade, além de incentivar atitudes éticas (PLETSCH et al., 2014).

As práticas sustentáveis das empresas são evidenciadas por meio das demonstrações financeiras ou pelos relatórios (COSTA, 2012). Garcia e Orsato (2013) destacam que cresce o número de empresas que divulgam relatórios de sustentabilidade com os padrões da Global Reporting Initiative (GRI).

Desenvolvimento sustentável não é somente sobre preservação ambiental, mas também aspectos sociais que proporcionem o bem-estar coletivo, essencial para a continuidade da vida (MOLINA, 2019). Apesar disso, as empresas que se declaram sustentáveis se preocupam mais com a questáo ambiental do que com as sociais, que deveriam ser incluídas nas políticas das empresas (CASAGRANDA; SAUER; PEREIRA, 2016). Apesar de não ser obrigatório, as empresas optam por divulgar dados relativos a questóes ambientais para obterem vantagem competitiva (FERREIRA et al., 2016). Porém, as informaçóes ambientais não são necessariamente, auditadas, o que póe em dúvida a credibilidade das mesmas (MUSSOI; VAN BELLEN, 2010).

As empresas procuram expressar as questóes socioambientais e de governança a seus stakeholders, e uma das formas de fazê-lo é se candidatando a carteira do ISE B3, passando por criteriosa avaliação (BERTÃO, 2020) por meio de questionário enviado pela B3 que envolve aspectos sociais, ambientais e econômico-financeiros representando o tripé da sustentabilidade (B3, 2019). 
O Índice de Sustentabilidade Empresarial (ISE B3) é composto por empresas de variados setores. As 200 ações mais líquidas da Bolsa de Valores Brasileira (Brasil, Bolsa, Balcão, B3) são convidadas a responder um questionário com dimensóes voltadas para a sustentabilidade e se quiserem participar; respondem ao documento, comprovam as respostas, pagam uma taxa que pode chegar a $\mathrm{R} \$ 30.000,00$ e, enviam para o comitê do ISE B3. De todas as empresas que responderem/enviarem, o ISE B3 seleciona aquelas que melhor representam açóes sustentáveis de acordo com sua metodologia. O grupo é composto normalmente por cerca de 30 a 40 empresas (ISE, 2015).

Todas as empresas podem participar da seleção, as que atuam no mercado interno (nacional) e externo (exportador), nos quais é possível verificar suas atitudes sustentáveis, porém, de acordo com Teles et al. (2016), aquelas que exportam possuem melhor desempenho socioambiental, fato que decorrer da concorrência e da exigência do mercado. Apesar de as empresas exportadoras se preocuparem mais com a sustentabilidade, a dimensão ambiental é determinante para a entrada delas em mercados internacionais, o que sugere que aquelas que exportam têm maior preocupação ambiental (PALMA et al., 2014; FLORES; GAVRONSKI, 2016).

As empresas exportadoras são atingidas pelas exigências de Padróes Voluntários de Sustentabilidade (PVS), as quais reduzem a competitividade das que não as adotam e melhoram a visão internacional das que as adotam melhorando seu desempenho social, ambiental e econômico. Além disso, tais padróes possibilitam às empresas não somente melhora na sua imagem, mas também em seus produtos, facilitando o acesso de empresas em novos mercados (MOREIRA, 2018).

Desta forma, emerge a questão da pesquisa: Como se dá a coerência do discurso sobre sustentabilidade das empresas que exportam e das que comercializam no mercado nacional? Para responder ao questionamento, como objetivo, esta pesquisa tem interesse em verificar a coerência do discurso sobre sustentabilidade das empresas que exportam e das que comercializam no mercado nacional.

A pesquisa se justifica pelo fato de investidores e consumidores se preocuparem em investir e serem clientes de empresas que possuam políticas de sustentabilidade na sua gestão, além das exportadoras parecerem se preocupar mais com sustentabilidade, porém algumas das informaçóes não são, obrigatoriamente, auditadas, as pondo em dúvida (DIAS et al., 2020; ROCHA et al., 2019; TELES et al., 2016; PALMA et al., 2014; MUSSOI; VAN BELLEN, 2010).

Dessa forma, a presente pesquisa contribui para que os stakeholders avaliem se o que as empresas declaram nos questionários possui coerência, bem como quais são os aspectos em que elas são mais coerentes, em relação àquelas que exportam e às participantes do mercado nacional. Assim, os stakeholders podem ter visão de como é tratada a sustentabilidade por parte das empresas, visto que a pesquisa aborda o tema em sentido geral (social, ambiental e econômico-financeiro). 


\section{REFERENCIAL TEÓRICO}

\subsection{Sustentabilidade Empresarial}

O termo sustentabilidade ganhou visibilidade a partir de 1987, quando foi publicado, pela Organização das Naçóes Unidas (ONU), o Relatório Brundtland, assim, o conceito de sustentabilidade traz a ideia de desempenho financeiro respeitando a sociedade e o meio ambiente. Ser sustentável sob a perspectiva empresarial é obter lucros de modo que adicione valor para a sociedade e minimize os impactos ambientais negativos (COLARES et al., 2012).

A partir da publicação do Relatório Brundtland, o tema sustentabilidade foi abordado para diminuir os efeitos das atividades humanas no meio ambiente. Seguindo a linha de pensamento Triple Bottom Line, a sustentabilidade empresarial possui três dimensóes: social, ambiental e econômico-financeira, devendo as empresas medirem as geraçóes de valor e os prejuízos por elas provocados nos âmbitos social e ambiental (ORIDE; MYSZCZUK, 2017). Para verificar se os países e empresas são sustentáveis foi necessário criar indicadores e assim se estabelecerem políticas (MOLINA, 2019).

Buscando promover um ambiente em que o lucro e a sustentabilidade estejam alinhados nas empresas, em 2005 foi criado pela antiga Bovespa, atual B3, o ISE B3 que compara a performance das empresas listadas sob o aspecto da sustentabilidade corporativa, baseada em eficiência econômica, equilíbrio ambiental, justiça social e governança corporativa. Além disso, proporciona destaque internacional para empresas e grupos comprometidos com a sustentabilidade, diferenciando-os em termos de qualidade, nível de compromisso com o desenvolvimento sustentável, equidade, transparência e prestação de contas, natureza do produto, além do desempenho empresarial nas dimensóes econômicofinanceira, social, ambiental e mudança do clima (B3, 2019).

Ainda, o ISE auxilia na tomada de decisão pelos investidores que se preocupam com a sustentabilidade. $\mathrm{O}$ índice segue quatro princípios: o primeiro preza pela transparência do processo do ISE, bem como das respostas ao questionário pelas empresas, o segundo busca o diálogo com a sociedade e as partes interessadas, o terceiro princípio se refere à atualizaçáo do questionário e do aperfeiçoamento do processo, já o quarto visa autonomia financeira, metodológica e decisória (SOUZA et al., 2019).

No ano de 2015, se criou uma ferramenta para auxiliar a integrar a sustentabilidade nas empresas: Os 17 Objetivos de Desenvolvimento Sustentável (ODS) que concretizam direitos humanos a todos e visam unir as dimensóes econômica, social e ambiental abrangendo 169 metas, compondo a Agenda 2030 que pretende com que todos tenham oportunidades de participar plenamente da sociedade, além de destacar que o desenvolvimento sustentável só pode ser com segurança e paz (BELLUZZO, 2018). Para se adaptar às mais recentes discussóes sobre sustentabilidade, o questionário do ISE de 2018 englobou os ODS, além disso, em 2019 a B3 apresentou o whitepaper intitulado "A Experiência do ISE B3 na Agenda 2030 e nos ODS”, o qual detalha a adoção dos ODS no processo seletivo da carteira do ISE, além dos resultados a partir das respostas dadas ao questionário (B3, 2020). 


\subsection{Evidenciação Socioambiental e Mercado Nacional e Exportador}

A partir de 1992, com a Conferência das Naçóes Unidas sobre o Meio Ambiente e Desenvolvimento, as empresas precisaram se adaptar às mudanças que ocorrem na forma de desenvolvimento, levando em consideração os impactos de suas atividades no meio ambiente e na sociedade. As pressóes da sociedade motivaram as empresas a divulgar seu desempenho e impactos, além de informaçóes sobre ativos intangíveis que tem papel relevante na determinação do valor da empresa (NAGANO et al., 2013). Foi também a partir de 1992 que o tema "meio ambiente" ganhou visibilidade no âmbito político, sendo a Conferência considerada marco simbólico (ORIDE; MYSZCZUK, 2017).

De acordo com Souza et al. (2019) conforme as empresas se dizem sustentáveis, surge a necessidade de divulgar informaçóes que comprovem sua veracidade, e deste modo emerge a contabilidade mostrando seu papel na informação aos usuários. Assim, a evidenciação das informaçôes contábeis é relevante (SANTOS-CORRÊA et al., 2013).

A evidenciação socioambiental, para Maçambanni et al. (2013) é uma ferramenta que supre as demandas de informaçóes dos usuários. Tais usuários são mais exigentes em relação às informaçóes divulgadas, pressionando as empresas a tomarem posturas sustentáveis, assim elas passaram a divulgar temas como responsabilidade social e ambiental (NUNES; TEIXEIRA; NOSSA, 2010; EUGÉNIO, 2010). A sustentabilidade pode ser avaliada por meio de indicadores que apresentam informaçôes não somente sobre questóes ambientais, mas também em relação a questôes sociais, e por tais indicadores se estabelecem políticas de sustentabilidade e comparação de resultados (MOLINA, 2019).

As informações ambientais são diferentes em suas qualidades e quantidades de acordo com o relatório socioambiental que possui informaçóes mais relevantes e é o mais completo. Os principais fatores que influenciam a divulgação de informações ambientais voluntárias vão desde o negócio ao mercado, com pressôes de clientes e fornecedores, até legislaçôes e iniciativas mundiais, como leis e acordos dentro ou fora do país. Apesar de trazerem custos para a empresa, a divulgação voluntária de informações ambientais proporciona benefícios para a companhia, como moral de seus colaboradores e proporciona maior confiança para seus stakeholders, assim devem ser levados em conta ao escolher sua forma de transparência (MUSSOI; VAN BELLEN, 2010). Segundo Rover et al. (2008) é necessária regulamentação em relação à divulgação de informações ambientais, o que traria confiança para os interessados nas mesmas, além de serem auditados.

A sustentabilidade empresarial tem destaque maior para a questão ambiental e econômico-financeira e pouco enfoque para a questão social, que se fosse incluída nas organizaçóes traria benefícios para a empresa e sociedade, sejam eles no curto ou longo prazo, o que demonstra que tal tema é tratado superficialmente (CASAGRANDA et al., 2016). Segundo Oride e Myszczuk (2017), a sustentabilidade no âmbito ambiental, além de ser mais relacionada ao tema, é uma consequência dos processos adotados pelas empresas de redução de custos e despesas. Tamanho, ISE, alavancagem e internacionalização explicam a divulgação voluntária de informações ambientais por parte das empresas (AZEVEDO et al., 2019). Segundo Souza, Rásia e Jacques (2010), quando a consciência ambiental faz parte da cultura e do plano de ação das empresas, melhora seu desempenho, fortalece sua imagem e torna seu processo produtivo mais eficiente e com redução de perdas. 
De acordo com Ferreira (2017), o disclosure e os investimentos socioambientais das empresas são influenciados por acidentes causados por elas, além desses acidentes influenciarem as do mesmo setor das causadoras. Recentemente, ocorreu o rompimento da barragem de Brumadinho, cuja empresa responsável a Vale S.A. foi excluída do ISE após o acidente (FORBES, 2019).

Investir em práticas sustentáveis, melhores condições para seus empregados e adotar políticas sustentáveis devem, segundo Berlato, Saussen e Gomez (2016), fazer parte da gestáo das empresas por elas serem parte integrante da sociedade, tendo em vista que os consumidores buscam empresas responsáveis ambiental e socialmente, criando vínculo de confiança com a companhia. Além de possibilitar maior visibilidade no mercado, gerando vantagem competitiva frente aos concorrentes, as empresas sustentáveis podem se beneficiar de uma maior eficiência na sua produção por meio de reutilização e controle de desperdícios ainda incentivando seus clientes a serem sustentáveis (ORIDE; MYSZCZUK, 2017). Apesar disso, muitas empresas se declaram socialmente responsáveis, porém nem todas evidenciam seus investimentos sociais. Ainda, com relação às empresas que compóem a carteira do ISE, 11,8\% delas não divulgam informaçóes financeiras em relação ao valor que foi gasto em atividades sociais, já em relaçáo às organizaçóes vinculadas a externalidades negativas, esse número é $72,2 \%$, o que gera dúvidas sobre a existência desses investimentos (MILANI FILHO, 2008).

Com a abertura do mercado nacional para empresas estrangeiras, as nacionais buscam exportar seus produtos, além disso, procuram participar do mercado externo para obterem recursos e eficiência, passando por obstáculos, como taxa cambial elevada, produtos mais baratos, legislaçáo externa, entre outros, dificultando o processo. Produtos diferenciados, com maior qualidade e tecnologia, além da sustentabilidade, agregando valor econômico, social e ambiental, sáo algumas das vantagens competitivas que as empresas que exportam possuem em relação às demais, que são essenciais para que participem do mercado externo (PAULA; FERREIRA; QUINTE, 2019).

O mercado externo exige que as empresas adotem uma postura sustentável em seus negócios, além de adaptar seus produtos de acordo com as exigências, o que se torna um desafio para exportadores, porém as que adotam medidas voluntárias para informar aos seus públicos os impactos socioambientais causados por sua atividade, criam reputação de empresa responsável e obtêm vantagem competitiva no mercado internacional (PALMA et al., 2014; FLORES; GAVRONSKI, 2016).

Apesar disso, Teles et al. (2016) consideram que existem desafios associados ao desenvolvimento sustentável, assim, propuseram um método para avaliar a sustentabilidade das empresas empregando suporte analítico e gráfico, cujos resultados apontam que as empresas possuem desempenho socioambiental melhor externamente, o que pode ser explicado pela preocupação com sua imagem, além de as empresas exportadoras possuírem desempenho socioambiental melhor se comparado a empresas atuantes no mercado interno.

A partir de 1990 surgiu o conjunto de sistemas de gestão ambiental (SGA) que evita ou minimiza os impactos ambientais das empresas, indo além do que exige a legislação e sendo de maior abrangência do que os "selos verdes". Além disso, empresas que exportam obtém vantagem competitiva ao adotar tais sistemas, porém é necessário que haja um 
processo de auditoria para dar maior credibilidade a esses sistemas (SANTOS; SEHNEM; FREITAS, 2015).

\section{METODOLOGIA}

O estudo é uma pesquisa documental, qualitativa, que utiliza a técnica de análise de conteúdo no discurso das empresas e suas açôes sustentáveis, na dimensão geral do questionário sugerido pela B3. A análise de conteúdo foi proposta por Bardin (2011) e consiste em aplicar ao discurso (respostas dadas ao questionário) instrumentos metodológicos a fim de verificar a presença ou a ausência de uma determinada informação (dados que respondam as perguntas do questionário), apresentando os aspectos em que as empresas parecem se preocupar quando o assunto é sustentabilidade empresarial.

O ISE, índice de retorno total, do qual foram extraídas as empresas consideradas na amostra é o resultado de uma carteira teórica de ativos, elaborada de acordo com os critérios pré-estabelecidos e que utilizam procedimentos e regras constantes do Manual de Definiçôes e Procedimentos dos Índices da BM\&FBOVESPA (ISE, 2015). O ISE é um indicador do desempenho médio das cotaçóes dos ativos de empresas com reconhecido comprometimento com a sustentabilidade empresarial.

O ISE B3 é composto de açôes de companhias listadas na B3 que obedeçam cumulativamente a critérios de inclusão e se necessário são sujeitas aos de exclusão da carteira (Quadro 1).

Quadro 1 - Critérios de inclusão e exclusão de empresas da carteira.

\section{Critérios de inclusáo}

Estar entre os ativos elegíveis que, no período de vigência das 3 (três) carteiras anteriores, em ordem decrescente de Índice de Negociabilidade (IN), ocupem as 200 primeiras posiçóes.

Ter presença em pregão de 50\% (cinquenta por cento) no período de vigência das 3 (três) carteiras anteriores.

Não ser classificado como "Penny Stock".

Atender aos critérios de sustentabilidade e ser selecionado pelo Conselho Deliberativo do ISE.

Uma vez que um ativo de uma empresa atenda aos critérios de inclusão acima, todas as espécies de sua emissão participarão da carteira do índice, desde que estejam entre os ativos elegíveis que, no período de vigência das 3 (três) carteiras anteriores, em ordem decrescente de Índice de Negociabilidade (IN), representem em conjunto 99\% (noventa e nove por cento) do somatório total desses indicadores.

\section{Critérios de exclusão}

Atender aos critérios de sustentabilidade e ser selecionado pelo Conselho Deliberativo do ISE.

Durante a vigência da carteira passem a ser listados em situação especial (Serão excluídos ao final de seu primeiro dia de negociação nesse enquadramento).

Forem de emissão de uma empresa cujo desempenho de sustentabilidade, no entendimento do Conselho Deliberativo do ISE (CISE), tenha sido significativamente alterado em função de algum acontecimento ocorrido durante a vigência da carteira. Nesse caso, os ativos serão excluídos, a qualquer momento, por deliberação do CISE.

Fonte: ISE (2015). 
A metodologia considera ainda os critérios de ponderação, pois no ISE, os ativos são ponderados pelo valor de mercado do "free float" (ativos que se encontram em circulação). Ressalta-se que a participação de um setor econômico no ISE não poderá ser superior a $15 \%$, quando de sua inclusão ou nas reavaliações periódicas (ISE, 2015). Para a presente pesquisa utilizou-se os relatórios de sustentabilidade e anual e as respostas dos questionários propostos pela B3 às 28 empresas pertencentes a carteira do ISE B3 de 2019.

O questionário é organizado em sete grandes dimensóes que, em seu conjunto, abrangem a temática da sustentabilidade no que se considera relevante para esse processo seletivo e aplicável a empresas como as que dele participam. Ressalta-se, portanto, que o questionário pode não incluir aspectos que, mesmo importantes, não sejam necessários ou adequados à finalidade específica de selecionar empresas listadas para integrar a carteira ISE B3 (ISE, 2018).

Inicialmente se realizou uma busca pelos questionários aplicados às empresas e suas respostas no website oficial do ISE, por abranger o tema sustentabilidade em seus três aspectos e se optou pelo questionário da categoria geral que identifica em que medida uma companhia tem a sustentabilidade incorporada de forma fundamentada e estruturada em seus modelos de negócios e perspectivas futuras (ISE, 2018). Tal dimensão avalia o alinhamento estratégico da companhia com a sustentabilidade, e trata de seus compromissos fundamentais com a sustentabilidade, buscando otimizar os impactos materiais gerados pelo negócio. Procura identificar a forma como a empresa trata a sustentabilidade na natureza dos negócios que opera, nos modelos de negócio, nas estratégias, na cultura e nos valores da empresa. As empresas foram classificadas em 01 (um) exportadoras e 02 (dois) que comercializam no mercado nacional e estão apresentadas (em ordem alfabética) na Tabela 1:

Tabela 1 - Empresas e seus respectivos grupos.

\begin{tabular}{c|c|c|c}
\hline Empresa & Grupo & Empresa & Grupo \\
\hline AES Tietê & 2 & Engie & 2 \\
\hline Banco do Brasil & 2 & Fleury & 2 \\
\hline Bradesco & 2 & Itaú Unibanco & 2 \\
\hline Braskem & 1 & Itausa & 2 \\
\hline B2W Digital & 2 & Klabin & 1 \\
\hline CCR S.A. & 2 & Light & 2 \\
\hline Cielo & 2 & Lojas Americanas & 2 \\
\hline Cemig & 2 & Lojas Renner & 2 \\
\hline Copel & 2 & MRV & 2 \\
\hline Duratex & 1 & Natura & 1 \\
\hline Eletrobras & 2 & Santander & 2 \\
\hline Ecorodovias & 2 & Telefônica Brasil & 2 \\
\hline EDP Energias do Brasil & 2 & Tim & 2 \\
\hline Eletropaulo & 2 & Weg & 1 \\
\hline
\end{tabular}

Fonte: Elaboração própria. 
Em seguida, as respostas para as perguntas da categoria geral do questionário aplicado pelo ISE foram verificadas nos relatórios de sustentabilidade e anual divulgados, e ainda se tais informaçóes estavam de acordo com as respostas fornecidas pelas empresas.

O Quadro 2 apresenta a adequação ao método que respeita as três fases fundamentais propostas por Bardin (2011):

Quadro 2 - Adequação das fases do método da análise de conteúdo (BARDIN, 2011).

\begin{tabular}{|c|}
\hline Pré-Análise \\
\hline $\begin{array}{l}\text { Nesta etapa foi obtido o questionário da seleção para participar do ISE B3 para as empresas no ano de } \\
2018 \text { que compôe a carteira ISE B3 de } 2019 \text {, referente à dimensão geral, além dos relatórios anuais } \\
\text { e de sustentabilidade ou semelhantes das empresas do mesmo ano. As informaçóes sobre políticas } \\
\text { específicas, quando não encontradas nos relatórios, foram coletadas nos websites das empresas. As } \\
\text { empresas foram segregadas em dois grupos, sendo classificadas em } 01 \text { (um) quando exportam e } 02 \\
\text { (dois) quando comercializam no mercado nacional. Ainda, respeita as condiçóes de: exaustividade } \\
\text { (todas as perguntas do questionário foram observadas sem omissôes); a representatividade (a amostra } \\
\text { representa o universo das empresas referentes à carteira do ISE B3 de 2019); a homogeneidade (os } \\
\text { dados referem-se ao mesmo tema, foram obtidos por técnicas iguais e colhidos por indivíduos } \\
\text { semelhantes); a pertinência (os documentos são referentes ao conteúdo e objetivo da pesquisa) e a } \\
\text { exclusividade (um elemento náo foi classificado em mais de uma categoria). }\end{array}$ \\
\hline Exploraçáo do Material \\
\hline $\begin{array}{l}\text { Os dados foram analisados de modo a verificar se as empresas respondiam seus relatórios em } \\
\text { concordância com as respostas dadas ao questionário respondido. }\end{array}$ \\
\hline Tratamento dos resultados \\
\hline $\begin{array}{l}\text { Inferência e interpretação: por fim, os dados foram tabulados a fim de verificar a porcentagem } \\
\text { das empresas que são coerentes em suas respostas (de modo que se a pergunta do questionário } \\
\text { possuía várias alternativas e não foi possível verificar uma dessas alternativas, entáo a resposta foi } \\
\text { considerada em desacordo), além de apresentar quais são os aspectos aos quais as empresas são mais } \\
\text { transparentes analisando separadamente exportadoras e participantes do mercado nacional. }\end{array}$ \\
\hline
\end{tabular}

Fonte: Adaptado de Bardin (2011).

O Quadro 3 apresenta os critérios e indicadores nos quais as questóes analisadas foram baseadas:

Quadro 3 - Critérios e indicadores analisados.

\begin{tabular}{|c|c|}
\hline \multicolumn{2}{|c|}{ Critério I - Compromissos (compromissos que a empresa adota) } \\
\hline Indicador 1 & Compromisso Fundamental \\
\hline Indicador 2 & Compromissos Públicos Voluntários \\
\hline Critério II - Alinhamento (tratamento dos compromissos adotados) \\
\hline Indicador 3 & Consistência dos Compromissos \\
\hline Indicador 4 & Engajamento com Partes Interessadas \\
\hline Indicador 5 & Desempenho e Reconhecimento \\
\hline Critério III - Perspectiva Estratégica (estratégias envolvendo sustentabilidade) \\
\hline Indicador 6 & Estratégia e Posicionamento \\
\hline Indicador 7 & Cadeia de Valor \\
\hline
\end{tabular}




\begin{tabular}{|c|c|}
\hline Critério IV - Ética e Transparência (formas de transparência e combate a irregularidades) \\
\hline Indicador 8 & Defesa da Concorrência \\
\hline Indicador 9 & Prevenção e Combate à Corrupção \\
\hline Indicador 10 & Participação Pública \\
\hline Indicador 11 & Transparência \\
\hline
\end{tabular}

Fonte: Elaboração própria.

A partir dos critérios e indicadores realizou-se a busca das respostas nos relatórios de sustentabilidade e anual e websites das empresas e em seguida foram verificadas se as respostas fornecidas pelas mesmas e as do questionário entregue coincidiam, os relatórios que não passaram por processo de auditoria foram tomados também como verdade.

Esta adequação será verificada e demonstrada em percentual, de modo que 100\% representa que todas as empresas responderam ao questionário e, da mesma maneira apresentaram essas informaçóes em seus relatórios. Além disso, foram apresentados os itens que as empresas mais divulgam em cada critério e se é apresentado o gerenciamento desses itens, bem como o funcionamento dos sistemas e políticas internamente.

\section{RESULTADOS E ANÁLISES}

Para participarem do ISE B3, as empresas respondem ao questionário enviado pela B3 com informaçôes que possibilitem a sua verificação. Para a análise foram consideradas coerentes e/ou adequadas, as respostas examinadas nos relatórios de sustentabilidade e anual e websites das empresas que são idênticas às respondidas no questionário entregue para a participação da seleção da carteira ISE.

Os critérios do questionário e os percentuais de adequação com os relatórios divulgados pelas empresas estão apresentados na Tabela 2:

Tabela 2 - Adequação das respostas por critério.

\begin{tabular}{l|c|c}
\hline \multicolumn{1}{c|}{ Critério } & Grupo 1 (Exportadoras) & Grupo 2 (Nacionais) \\
\hline I - Compromissos & $89 \%$ & $86 \%$ \\
\hline II - Alinhamento & $97 \%$ & $93 \%$ \\
\hline III - Perspectiva Estratégica & $91 \%$ & $87 \%$ \\
\hline IV - Ética e Transparência & $93 \%$ & $86 \%$ \\
\hline
\end{tabular}

Fonte: Elaboração própria.

A avaliação dos dados gerais, de acordo com cada item, sugere que o critério II Alinhamento, foi o que as empresas se mostraram mais coerentes em suas respostas, já o critério I - Compromissos, o que menos apresentou coerência. Essas informações apontam que as empresas parecem divulgar mais como o tema sustentabilidade é tratado com as partes interessadas. Tal divulgação se dá por meio de indicadores de sustentabilidade, princípios de relacionamento e como os integra aos seus colaboradores, o que segundo Garcia e Orsato (2013) auxilia na tomada de decisão das partes interessadas de seus compromissos fundamentais e como os agrega na sua cultura, valores, estratégias e governança. 
Os resultados por critério sugerem ainda que as empresas que exportam são mais coerentes em suas respostas, visto que em todos os critérios analisados apresentaram, percentualmente, maior coerência nas respostas; tal constatação pode ser explicada pela exigência do mercado externo, corroborando Azevedo et al. (2019), que afirma ser uma busca por vantagem competitiva, já que seus produtos concorrem com mais empresas do que no mercado nacional, confirmando os dizeres de Teles et al. (2016).

\subsection{Critério I - Compromissos}

O critério I informa como as empresas integram o desenvolvimento sustentável na sua cultura e estratégia, além do tratamento de seus compromissos voluntários e como utilizam a Agenda 2030 e os ODS. A Tabela 3 apresentada os percentuais de coerência das respostas para o critério I:

Tabela 3 - Adequação das respostas referentes ao critério I.

\begin{tabular}{l|c|c}
\hline \multicolumn{1}{c|}{ Pergunta } & Grupo 1 & Grupo 2 \\
\hline $\begin{array}{l}\text { 1. O compromisso com o Desenvolvimento Sustentável está formalmente } \\
\text { integrado na cultura e na estratégia da companhia? }\end{array}$ & $100 \%$ & $100 \%$ \\
\hline $\begin{array}{l}\text { 1.1. Se SIM para a PERGUNTA 1, onde este compromisso está formalmente } \\
\text { expresso? }\end{array}$ & $100 \%$ & $100 \%$ \\
\hline $\begin{array}{l}\text { 1.2. Se SIM para a PERGUNTA 1, quais dos sete temas centrais da } \\
\text { Norma ISO 26000, além de outros temas relevantes estáo expressamente } \\
\text { contemplados neste compromisso, levando em conta a realidade brasileira? }\end{array}$ & $100 \%$ & $100 \%$ \\
\hline $\begin{array}{l}\text { 1.3. Se SIM para a PERGUNTA 1, a companhia mantém programa de } \\
\text { sensibilizaçáo e educação sobre o tema? }\end{array}$ & $100 \%$ & $91 \%$ \\
\hline $\begin{array}{l}\text { 1.3.1 Se SIM para a PERGUNTA 1.3, participam de forma ativa deste } \\
\text { programa um número representativo de quais categorias de partes } \\
\text { interessadas? }\end{array}$ & $60 \%$ & $35 \%$ \\
\hline $\begin{array}{l}\text { 1.3.2 Se SIM para a PERGUNTA 1.3, este programa é implementado de } \\
\text { forma sistemática e estruturada, possuindo quais etapas? }\end{array}$ & $60 \%$ & $65 \%$ \\
\hline $\begin{array}{l}\text { 1.4. Com relação ao compromisso expresso na PERGUNTA 1, como é feita } \\
\text { sua divulgação ampla? }\end{array}$ & $100 \%$ & $100 \%$ \\
\hline $\begin{array}{l}\text { 1.5. Com relaçáo ao compromisso expresso na PERGUNTA 1, ao definir } \\
\text { uma visão de futuro bem como os desafios e incertezas que provavelmente } \\
\text { enfrentará no futuro ao perseguir sua estratégia, o que a companhia } \\
\text { vislumbra? }\end{array}$ & $100 \%$ & $100 \%$ \\
\hline $\begin{array}{l}\text { 2. A companhia é signatária formal e publicamente de compromissos } \\
\text { voluntários amplamente legitimados, relacionados a temas do } \\
\text { desenvolvimento sustentável materiais e relevantes para seus negócios, } \\
\text { comprometendo todas suas unidades, bem como todas suas subsidiárias ou } \\
\text { controladas? }\end{array}$ & $100 \%$ & $100 \%$ \\
\hline $\begin{array}{l}\text { 2.1 Se SIM para a PERGUNTA 2, a companhia integra tais compromissos } \\
\text { voluntários em suas estratégias, realizando autoavaliaçóes, monitorando e } \\
\text { publicando resultados referentes aos compromissos assumidos? }\end{array}$ & $60 \%$ & $70 \%$ \\
\hline
\end{tabular}




\begin{tabular}{l|c|c}
\hline \multicolumn{1}{c|}{ Pergunta } & Grupo 1 & Grupo 2 \\
\hline $\begin{array}{l}\text { 2.1.1 Se SIM para a PERGUNTA 2.1, a companhia estabelece metas de } \\
\text { melhoria para estes indicadores e estabelece planos de açáo para o seu alcance? }\end{array}$ & $60 \%$ & $70 \%$ \\
\hline $\begin{array}{l}\text { 3. A companhia utiliza a Agenda 2030 es ODS como referências para } \\
\text { identificar e integrar aspectos relevantes de sustentabilidade em seus negócios? }\end{array}$ & $100 \%$ & $100 \%$ \\
\hline $\begin{array}{l}\text { 3.1. Se SIM para a PERGUNTA 3, como a companhia identifica a relação } \\
\text { direta e relevante entre suas práticas empresariais e os ODS? }\end{array}$ & $100 \%$ & $100 \%$ \\
\hline $\begin{array}{l}\text { 3.2. Se SIM para a alternativa (b) da PERGUNTA 3.1, qual é a priorização } \\
\text { dos ODS realizado pela companhia? }\end{array}$ & $100 \%$ & $100 \%$ \\
\hline $\begin{array}{l}\text { 3.2.1. Em relaçáo ao conjunto de ODS marcados na coluna IV da } \\
\text { PERGUNTA 3.2, como a companhia gerencia? }\end{array}$ & $100 \%$ & $57 \%$ \\
\hline
\end{tabular}

Fonte: Elaboraçâo própria.

As empresas possuem compromissos socioambientais que são divulgados por meio dos relatórios disponibilizados na intranet e/ou outros canais direcionados ao público interno da companhia, publicados em área de livre acesso do website da empresa e versóes adicionais com mais clareza e de acordo com Milani Filho (2008), obtêm assim mais confiabilidade com os estrangeiros. Tais compromissos são: práticas leais de operação, promoção dos direitos humanos, melhoria das condiçóes de trabalho, emprego e renda, relaçóes responsáveis com a comunidade e seu desenvolvimento e combate a todas as formas de corrupção, expressos em: visão, código de conduta, objetivos e metas de desempenho socioambiental e políticas da organização; missão; e planejamento estratégico.

Além disso, elas afirmam manter programa de sensibilização e educação sobre o tema, porém, das empresas pertencentes ao grupo 2, 91\% contemplam a forma mais ampla do desenvolvimento sustentável, o que demonstra que as demais tratam o tema superficialmente, se aproximando do estudo de Casagranda et al. (2016), pois divulgam mais questóes ambientais do que sociais. Participam de tal programa os stakeholders das empresas, porém $60 \%$ das empresas do grupo 1 e $65 \%$ das do grupo 2 são coerentes com as respostas dadas ao questionário, já as demais citam stakeholders, mas não os especificam. Logo, se verificou que $60 \%$ daquelas do grupo 1 e $65 \%$ do grupo 2 fornecem detalhes suficientes a respeito do programa. Ainda, isso demonstra que empresas afirmam a existência de tais programas, porém, sem a clara evidenciação não é possível verificar o efetivo comprometimento e dimensionar as açóes da companhia com seus públicos, como o discutido por Milani Filho (2008). O mesmo autor afirma que apesar de no Brasil, grande parte das informaçóes referentes às atividades sociais das empresas serem divulgadas voluntariamente, somente a existência de políticas ou programas sociais não comprovam o comprometimento quando não há evidenciação dos fatos.

Todas as empresas possuem compromissos voluntários voltados ao desenvolvimento sustentável, além disso os integram em suas estratégias, contudo, $60 \%$ das empresas do grupo 1 e $70 \%$ das do grupo 2 publicam os resultados e/ou metas, as demais são omissas nesse quesito, o que dificulta seu acompanhamento pelos públicos que se interessam em saber se atingem seus objetivos, assim Azevedo et al. (2019) explicam que a divulgação ambiental é vista como um mecanismo que busca alinhar interesses dos diferentes públicos. 
O uso de agenda 2030 e ODS se dá em todas as empresas, seja por meio de análise dos possíveis impactos das atividades das mesmas ou por meio de uma apreciação de materialidade, priorizando ODS julgados mais relevantes e identificando as externalidades positivas e negativas de suas atividades, demonstrando assim que elas levam em conta os ODS nas suas práticas, buscando, segundo Belluzzo (2018), unir as dimensóes social, ambiental e econômica. Assim as empresas parecem demonstrar que são sustentáveis, pois, de acordo com Colares et al. (2012) obtêm lucros de modo que adicionem valor para a sociedade e minimizem o impacto ambiental negativo.

\subsection{Critério II - Alinhamento}

O critério II demonstra como as empresas tratam a sustentabilidade internamente, seja por meio de políticas ou processos estabelecidos. A coerência das respostas para o critério II está apresentada na Tabela 4:

Tabela 4 - Adequação das respostas referentes ao critério II.

\begin{tabular}{l|c|c}
\hline \multicolumn{1}{c|}{ Pergunta } & Grupo 1 & Grupo 2 \\
\hline $\begin{array}{l}\text { 4. A companhia possui uma estrutura formal de governança para a } \\
\text { sustentabilidade? }\end{array}$ & $100 \%$ & $100 \%$ \\
\hline $\begin{array}{l}\text { 4.1 Se sim para a PERGUNTA 4, qual a mais alta instância a quem a(s) } \\
\text { estrutura(s) formal(is) existente(s) se reporta(m) diretamente? }\end{array}$ & $100 \%$ & $91 \%$ \\
\hline $\begin{array}{l}\text { 5. A companhia possui instrumento formal estabelecendo que suas políticas e } \\
\text { procedimentos relativos à sustentabilidade sejam observados em todas as suas } \\
\text { unidades e controladas incluindo, se aplicável, sua operaçáo em outros países } \\
\text { em que se localizem ou atuem? }\end{array}$ & $100 \%$ & $100 \%$ \\
\hline $\begin{array}{l}\text { 6. A companhia realiza análise de materialidade para identificar os seus } \\
\text { temas mais relevantes do ponto de vista da sustentabilidade e esse processo é } \\
\text { conduzido com participaçáo das principais partes interessadas? }\end{array}$ & $100 \%$ & $100 \%$ \\
\hline $\begin{array}{l}\text { 7. A companhia acompanha sistematicamente seus indicadores de } \\
\text { sustentabilidade, independentemente de demandas específicas? }\end{array}$ & $100 \%$ & $100 \%$ \\
\hline $\begin{array}{l}\text { 7.1. Se SIM para alternativas (a), (b) e/ou (c) da PERGUNTA 7, como a } \\
\text { companhia gerencia? }\end{array}$ & $100 \%$ & $91 \%$ \\
\hline $\begin{array}{l}\text { 8. A companhia possui um processo de due diligence para conduzir a gestáo de } \\
\text { riscos reais e potenciais dos impactos adversos na sustentabilidade? }\end{array}$ & $100 \%$ & $100 \%$ \\
\hline $\begin{array}{l}\text { 9. A companhia tem Política Corporativa visando assegurar princípios para } \\
\text { o relacionamento com suas partes interessadas, buscando engajá-las em suas } \\
\text { atividades e decisóes? }\end{array}$ & $100 \%$ & $100 \%$ \\
\hline $\begin{array}{l}\text { 9.1 Se SIM para a PERGUNTA 9, quais partes interessadas estáo contempladas } \\
\text { nesta política? }\end{array}$ & $100 \%$ & $87 \%$ \\
\hline $\begin{array}{l}\text { 9.2 Se SIM para a PERGUNTA 9, quais práticas estão contempladas } \\
\text { explicitamente nesta política? }\end{array}$ & $60 \%$ & $26 \%$ \\
\hline $\begin{array}{l}\text { 10. Como a companhia integra aspectos de sustentabilidade em suas práticas } \\
\text { de gestáo de desempenho e reconhecimento? }\end{array}$ & $100 \%$ & $100 \%$ \\
\hline $\begin{array}{l}\text { 11. A companhia divulga a remuneração dos seus administradores (conselheiros } \\
\text { de administraçáo e diretores)? }\end{array}$ & $100 \%$ & $100 \%$ \\
\hline
\end{tabular}




\begin{tabular}{l|c|c}
\hline \multicolumn{1}{c|}{ Pergunta } & Grupo 1 & Grupo 2 \\
\hline $\begin{array}{l}\text { 12. A companhia divulga os tipos e os critérios de remuneração e benefícios } \\
\text { atribuídos aos seus administradores (conselheiros de administração e diretores)? }\end{array}$ & $100 \%$ & $100 \%$ \\
\hline $\begin{array}{l}\text { 13. A remuneraçáo variável (reajustes salariais diferenciados, bônus, prêmios) } \\
\text { está vinculada a metas de desempenho socioambiental da companhia? }\end{array}$ & $100 \%$ & $100 \%$ \\
\hline $\begin{array}{l}\text { 14. O sistema de remuneração variável da companhia prevê algum dispositivo } \\
\text { que propicie uma correlação entre os riscos assumidos, a remuneração } \\
\text { efetivamente paga e o resultado da companhia? }\end{array}$ & $100 \%$ & $100 \%$ \\
\hline
\end{tabular}

Fonte: Elaboração própria.

Apesar de todas as empresas afirmarem possuir estrutura formal de governança para a sustentabilidade, em relação ao grupo 2, 91\% divulgam informaçôes detalhadas sobre essa estrutura, como funcionamento e a quem se reporta.

Os indicadores de sustentabilidade são avaliados independentemente de demandas específicas, porém, das empresas pertencentes ao grupo 2, 91\% detalham a gestão desses indicadores, como por exemplo se utilizam os resultados para o apoio à tomada de decisão, bem como se é feito acompanhamento do histórico deles e sua evolução bem como é realizado o processo, além de prestar contas sobre tais indicadores. Assim, empresas mais transparentes contribuem para reduzir a assimetria informacional e de acordo com Milani Filho (2008) faz com que investidores externos confiem mais nelas.

Há política corporativa com princípios para o relacionamento com partes interessadas, porém $87 \%$ das empresas pertencentes ao grupo 2 são as que detalham quais são as partes interessadas, além de $60 \%$ das pertencentes ao grupo 1 e, $26 \%$ das do grupo 2 detalharem o gerenciamento dessas práticas.

As empresas integram aspectos de sustentabilidade na descrição de cargos, em suas metas de desempenho e ações de premiação e reconhecimento visando melhor alinhamento entre os interesses das partes, e procurando reduzir a assimetria de informaçóes, como destacado por Nunes et al. (2010).

\subsection{Critério III - Perspectiva Estratégica}

O critério III apresenta a visão estratégica das empresas abordando sustentabilidade e sua cadeia de valor. $\mathrm{Na}$ Tabela 5 é apresentada a coerência das respostas em relação ao critério III:

Tabela 5 - Adequação das respostas referentes ao critério III.

\begin{tabular}{l|c|c}
\hline \multicolumn{1}{c|}{ Pergunta } & Grupo 1 & Grupo 2 \\
\hline $\begin{array}{l}\text { 15. Existe processo institucionalizado de planejamento estratégico, aprovado } \\
\text { no âmbito do Conselho de Administraçáo ou, caso este inexista, da instância } \\
\text { mais elevada de gestão da companhia? }\end{array}$ & $100 \%$ & $100 \%$ \\
\hline $\begin{array}{l}\text { 15.1. Se SIM para a PERGUNTA 15, o que está formalmente considerado } \\
\text { neste processo institucionalizado de planejamento estratégico e refletido em } \\
\text { objetivos com seus respectivos indicadores e metas? }\end{array}$ & $100 \%$ & $91 \%$ \\
\hline
\end{tabular}




\begin{tabular}{|c|c|c|}
\hline Pergunta & Grupo 1 & Grupo 2 \\
\hline $\begin{array}{l}\text { 16. Qual o estágio em que se encontra a companhia em relação à adaptação } \\
\text { de seu negócio do ponto de vista da sustentabilidade, de forma a eliminar } \\
\text { ou minimizar externalidades negativas (econômicas, sociais e ambientais) e a } \\
\text { otimizar externalidades positivas? }\end{array}$ & $80 \%$ & $91 \%$ \\
\hline $\begin{array}{l}\text { 17. A comercializaçáa de bens de consumo semiduráveis e duráveis } \\
\text { corresponde a quanto no faturamento da companhia e de suas controladas? }\end{array}$ & $100 \%$ & $100 \%$ \\
\hline $\begin{array}{l}\text { 17.1. Se SIM para as alternativas (a) ou (b) da PERGUNTA 17, quais os } \\
\text { tratamentos dados? }\end{array}$ & $100 \%$ & $100 \%$ \\
\hline $\begin{array}{l}\text { 18. A companhia conhece e gerencia sua cadeia de valor, identificando e } \\
\text { atuando sobre os elos relevantes de acordo com o seu negócio e impactos } \\
\text { relacionados? }\end{array}$ & $100 \%$ & $100 \%$ \\
\hline $\begin{array}{l}\text { 18.1. Se SIM para a PERGUNTA 18, quais os elos da cadeia de valor que a } \\
\text { companhia conhece e monitora? }\end{array}$ & $100 \%$ & $91 \%$ \\
\hline $\begin{array}{l}\text { 19. Com relaçãoà adoção de práticas internas para incorporar a sustentabilidade } \\
\text { à estratégia de suprimentos visando promover a sustentabilidade na cadeia de } \\
\text { valor, o que melhor representa a atuaçáo da companhia, e os níveis em que } \\
\text { são aplicadas? }\end{array}$ & $60 \%$ & $57 \%$ \\
\hline $\begin{array}{l}\text { 20. A companhia possui processos e procedimentos implementados em } \\
\text { relação à aplicação de critérios socioambientais para identificação e gestão de } \\
\text { seus fornecedores críticos? }\end{array}$ & $100 \%$ & $100 \%$ \\
\hline $\begin{array}{l}\text { 20.1. Se SIM para PERGUNTA 20, quais os critérios e etapas do processo } \\
\text { cobertas pelos processos e procedimentos relativos à gestão dos fornecedores } \\
\text { críticos? }\end{array}$ & $80 \%$ & $74 \%$ \\
\hline $\begin{array}{l}\text { 21. A companhia possui processos e procedimentos implementados em } \\
\text { relaçáo à aplicaçáo de critérios socioambientais na gestáo dos principais } \\
\text { integrantes de sua cadeia de valor envolvidos no processo de venda, uso e/ou } \\
\text { pós-consumo de seus produtos? }\end{array}$ & $80 \%$ & $52 \%$ \\
\hline
\end{tabular}

Fonte: Elaboração própria.

Das empresas do grupo 2, 91\% delas detalham suficientemente os aspectos abordados em seu processo de planejamento estratégico, sejam impactos socioambientais de suas atividades e sua cadeia de valor, seu posicionamento diante desses impactos, além de interesses de terceiros e seus compromissos considerados relevantes.

As empresas conhecem e gerenciam sua cadeia de valor, porém $91 \%$ das empresas do grupo 2 especificam o processo de gestão de elos da cadeia de valor, dificultando o acompanhamento pelos stakeholders, os quais vêm pressionando as organizaçóes (Nunes et al., 2010). Práticas internas são adotadas para obter uma cadeia de valor sustentável, aumentando assim suas contribuiçóes para a sustentabilidade empresarial, porém $60 \%$ das empresas do grupo 1 e $57 \%$ das do grupo 2 detalham o gerenciamento dessas práticas.

Para identificar e gerir os fornecedores críticos, as empresas possuem processos e procedimentos implementados que aplicam critérios socioambientais para esses fornecedores, apesar disso, 80\% das empresas do grupo 1 e, 74\% das do grupo 2 detalham tais processos. Nessa linha, Milani Filho (2008) pontua que ao buscarem uma melhor relação com seus fornecedores, as empresas conseguem condições mais favoráveis na aquisição e no pagamento 
pelos insumos, o que eleva a competitividade delas. Já em relação à gestão de sua cadeia de valor envolvida na venda, uso e/ou pós-consumo de seus produtos, $80 \%$ das empresas pertencentes ao grupo 1 e $52 \%$ das pertencentes ao grupo 2 detalham tais procedimentos. Assim, sem detalhar os processos e procedimentos adotados, os stakeholders tem dificuldade em saber como as empresas gerenciam seus fornecedores críticos e integrantes da cadeia de valor que são responsáveis pela venda, uso e/ou pós-consumo, fazendo com que não tenham como verificar se os objetivos estáo sendo atingidos. Dessa forma, de acordo com Azevedo et al. (2019), as empresas brasileiras buscam atrair investidores estrangeiros e assim obtêm incentivo para melhorar suas divulgaçóes.

\subsection{Critério IV - Ética e Transparência}

O critério IV aborda condutas éticas e transparentes por parte da companhia e seus públicos e na Tabela 6 está apresentada a coerência das respostas relativas ao critério IV:

Tabela 6 - Adequação das respostas referentes ao critério IV.

\begin{tabular}{l|c|c}
\hline \multicolumn{1}{c|}{ Pergunta } & Grupo 1 & Grupo 2 \\
\hline $\begin{array}{l}\text { 22. A companhia adota política contínua de esclarecimento aos funcionários } \\
\text { sobre defesa da concorrência? }\end{array}$ & $100 \%$ & $100 \%$ \\
\hline $\begin{array}{l}\text { 22.1. Se SIM para a PERGUNTA 22, quais instrumentos são utilizados } \\
\text { pela companhia para implantar medidas de defesa da concorrência? }\end{array}$ & $40 \%$ & $35 \%$ \\
\hline $\begin{array}{l}\text { 23. A companhia possui compromisso formal em relação ao combate a } \\
\text { todas as formas de corrupçáo? }\end{array}$ & $100 \%$ & $100 \%$ \\
\hline $\begin{array}{l}\text { 23.1. Se SIM para as alternativas (a) e/ou (b) da PERGUNTA 23, o que } \\
\text { este compromisso formal diz? }\end{array}$ & $100 \%$ & $83 \%$ \\
\hline $\begin{array}{l}\text { 24. Em quais relaçóes a companhia atua de forma proativa e contínua na } \\
\text { conscientizaçáo de seu público interno e seus parceiros comerciais para a } \\
\text { prevenção e combate a todas as formas de corrupçáo? }\end{array}$ & $60 \%$ & $52 \%$ \\
\hline $\begin{array}{l}\text { 25. A companhia possui processos e procedimentos implementados que } \\
\text { permitem o gerenciamento de situaçôes envolvendo qualquer forma de } \\
\text { corrupção e/ou conflitos de interesses? }\end{array}$ & $100 \%$ & $100 \%$ \\
\hline $\begin{array}{l}\text { 25.1. Se SIM para a PERGUNTA 25, o que estes processos e procedimentos } \\
\text { incluem? }\end{array}$ & $100 \%$ & $78 \%$ \\
\hline $\begin{array}{l}\text { 26. A companhia procura concretizar seu compromisso com o } \\
\text { desenvolvimento sustentável atuando proativamente na elaboração, } \\
\text { avaliaçáa, implantaçáo ou monitoramento de políticas voltadas ao interesse } \\
\text { público, atuando nas instâncias competentes de forma transparente e } \\
\text { articulada com as demais partes interessadas? }\end{array}$ & $100 \%$ & $100 \%$ \\
\hline $\begin{array}{l}\text { 27. Ao participar da elaboraçáo, avaliação, implantação ou monitoramento } \\
\text { de políticas públicas, a companhia e/ou o órgáo de classe correspondente } \\
\text { adota práticas de transparência adequadas, dando publicidade às suas } \\
\text { propostas e posicionamentos? }\end{array}$ & $100 \%$ \\
$\begin{array}{l}\text { 28. Nos últimos 4 anos, a companhia financiou ou apoiou candidatos a } \\
\text { cargos públicos e/ou partidos políticos, dentro ou fora de períodos eleitorais? }\end{array}$ & $100 \%$ & $83 \%$ \\
\hline
\end{tabular}




\begin{tabular}{l|c|c}
\hline \multicolumn{1}{c|}{ Pergunta } & Grupo 1 & Grupo 2 \\
\hline $\begin{array}{l}\text { 28.1. Se SIM para a PERGUNTA 28, a companhia publica informação } \\
\text { completa a respeito dos valores, dos candidatos e dos partidos em seu } \\
\text { Relatório de Sustentabilidade ou na área de livre acesso de seu website ou } \\
\text { outro instrumento público? }\end{array}$ & $100 \%$ & $91 \%$ \\
\hline $\begin{array}{l}\text { 29. A companhia possui práticas internas de transparência para informar } \\
\text { sua força de trabalho sobre seu desempenho em aspectos materiais de } \\
\text { sustentabilidade? }\end{array}$ & $100 \%$ & $100 \%$ \\
\hline $\begin{array}{l}\text { 30. No último ano, a companhia publicou Relatório de Sustentabilidade? } \\
\text { 30.1. Se SIM para a PERGUNTA 30, o que este relatório traz? }\end{array}$ & $100 \%$ & $100 \%$ \\
\hline $\begin{array}{l}\text { 31. Em relação à produção de relatos baseados na integração entre } \\
\text { informaçóes econômicas, sociais, ambientais e de governança, como a } \\
\text { companhia trata o tema? }\end{array}$ & $100 \%$ & $100 \%$ \\
\hline
\end{tabular}

Fonte: Elaboração própria.

Apesar de adotarem política sobre defesa de concorrência, tal política apresenta detalhes sobre instrumentos utilizados para $40 \%$ das empresas pertencentes ao grupo $1 \mathrm{e}$ $35 \%$ das pertencentes ao grupo 2, entre esses instrumentos estáo: informativos internos; palestras, cursos e orientaçóes sobre o tema; e procedimentos que visem a identificação e correção de práticas anticompetitivas. As empresas possuem compromisso formal de combate a todas as formas de corrupção, indo além do cumprimento da legislação, porém, das empresas pertencentes ao grupo 2, 83\% detalham o gerenciamento dessas questóes. Considerando que existem diferentes situações em que possa ocorrer corrupção, as empresas atuam de forma proativa e contínua a fim de conscientizar seu público interno além de seus parceiros comerciais sobre prevenção e combate à corrupção em todas as formas, porém $60 \%$ das empresas do grupo 1 e $52 \%$ das do grupo 2 detalham em quais relaçóes especificamente atuam. Apesar de possuírem processos e procedimentos para gerenciar situaçóes envolvendo corrupção e/ou conflitos de interesse, no grupo 2, 78\% das empresas detalham os procedimentos adotados. Dessa forma, se verifica que as empresas afirmam que combatem essas irregularidades, porém, quando não é evidenciado tal fato, é difícil constatar o efetivo comprometimento das companhias com relação ao tema, corroborando Milani Filho (2008).

Quando participam de elaboração, avaliação, implantação ou monitoramento de políticas públicas, $100 \%$ das empresas do grupo 1 e, $83 \%$ das do grupo 2 dão publicidade às suas propostas e posicionamentos.

Em relação ao apoio dado pelas empresas, das pertencentes ao grupo 2, 91\% dos casos estão de acordo com as respostas dadas ao questionário, as demais apresentaram informaçóes divergentes.

Todas as empresas divulgaram relatório de sustentabilidade, o qual apresentou o desempenho da companhia não somente no aspecto financeiro, mas também ambientais, sociais e de governança corporativa. Tal relatório inclui parecer de auditor externo e independente sobre a totalidade de seu conteúdo em $80 \%$ das empresas do grupo 1 e em $87 \%$ das empresas do grupo 2, apesar de o processo de auditoria não ser obrigatório, o que segundo Mussoi e Van Bellen (2010) demonstra que essas empresas parecem estar 
preocupadas em dar credibilidade aos relatórios e indo a favor da necessidade apontada por Rover et al. (2008) de passarem por esse processo.

\section{CONSIDERAÇÓES FINAIS}

O presente trabalho analisou a coerência do discurso sobre sustentabilidade das 28 empresas listadas no ISE na carteira de 2019, segregando a amostra em empresas que exportam e participantes do mercado nacional. Para tanto, foi aplicada a análise de conteúdo do discurso (BARDIN, 2011) das empresas e suas açóes sustentáveis.

Os achados evidenciaram que as empresas analisadas transparecem ser sustentáveis, confirmando os estudos de Donaire (1994) e Milani Filho (2008) e, coerentes em seu discurso, de acordo com a declaração de suas iniciativas, como projetos sociais para a comunidade além de medidas internas de controle e de conscientização para que sejam usados recursos naturais de forma racional. Os principais aspectos que as empresas vêm divulgando são: como a sustentabilidade é tratada com as partes interessadas; gerenciamento de sua cadeia de valor e monitoramento de seus elos; formas de transparência, divulgando informaçóes de fácil acesso; combate a irregularidades como corrupção; participação ativa na sociedade por meio de projetos e parcerias; e passagem dos relatórios publicados sobre sustentabilidade por processo de auditoria, o que proporciona maior credibilidade às informaçóes, conforme destacado por Rover et al. (2008).

Além disso, foi observado que empresas exportadoras parecem mais coerentes com suas respostas se comparadas àquelas que comercializam no mercado nacional, o que pode ser explicado pelo fato de que as exportadoras possuem maior preocupação socioambiental e em relação à sua imagem nos mercados em que comercializam, seguindo os estudos de Palma et al., (2014), Flores e Gavronski (2016) e Teles et al. (2016).

Os resultados contribuem para que os stakeholders tenham mais confiança no discurso das empresas com as quais possuem ligação, visto que $80 \%$ das empresas do grupo 1 e $87 \%$ das do grupo 2 tiveram seus relatórios sobre sustentabilidade auditados, além de saberem quais são as preocupaçóes das mesmas com o tema, seja para investidores que buscam empresas comprometidas, clientes, para que saibam os impactos dos produtos consumidos e serviços prestados, além de outros públicos que se relacionam com as mesmas. A pesquisa, pelo fato de as empresas pertencerem ao ISE, não permite generalizaçóes para àquelas que não pertençam ao índice.

Para futuras pesquisas sugere-se que sejam analisadas paralelamente empresas do ISE, com a separação entre as que exportam e não exportam, e demais empresas em igual número, para verificar se existe diferença significativa entre elas com relação à coerência das informações.

\section{Referências}

AZEVEDO, Yuri Gomes Paiva et al. Divulgação voluntária de informações ambientais: uma análise dos fatores determinantes nas empresas listadas na BM\&FBovespa.

Sociedade, Contabilidade e Gestáo, v. 14, n. 1, p. 1-17, 2019. 
BARDIN, Laurence. Análise de Conteúdo. São Paulo: Ed. Revista Ampliada, 2011.

BELlUZZO, Regina Célia Baptista. Competência em informação (CoInfo) e midiática: inter-relação com a Agenda 2030 e os Objetivos de Desenvolvimento Sustentável (ODS) sob a ótica da educação contemporânea. Folha de Rosto, v. 4, n. 1, p. 15-24, 2018.

BERLATO, Larissa Fontoura; SAUSSEN, Fabiane; GOMEZ, Luiz Salomão Ribas. A sustentabilidade empresarial como vantagem competitiva em Branding. DAPesquisa, v. 11, n. 15, p. 024-041, 2016.

BERTÃO, N. Índice sustentável da bolsa bate recorde de interesse e três novas empresas entram na carteira de 2020. Disponível em: https://valorinveste.globo.com/ mercados/renda-variavel/bolsas-e-indices/noticia/2019/11/29/indice-sustentavel-da-bolsabate-recorde-de-interesse-e-tres-novas-empresas-entram-na-carteira-de-2020.ghtml. Acesso em 01 jun. 2020.

BRASIL, BOLSA, BALCÃO, B3. A experiência do ISE na Agenda 2030 e os ODS. Net, São Paulo. Disponível em: http://iseb3.com.br/a-experiencia-do-ise-na-agenda-2030e-os-ods. Acesso em: 01 jun. 2020.

BRASIL, BOLSA, BALCÃO, B3. Índice Empresarial de Sustentabilidade (ISE). Net, São Paulo. Seção Sobre. Disponível em: http://iseb3.com.br/. Acesso em: 25 set. 2019.

BRASIL, BOLSA, BALCÃO, B3. Metodologia do Índice de Sustentabilidade Empresarial (ISE). Net, São Paulo. Seção Sobre. Disponível em: https://www.b3.com. br/data/files/B2/F2/C9/24/98E615107623A41592D828A8/ISE-Metodologia-pt-br.pdf. Acesso em: 15 out. 2021.

BRASIL, BOLSA, BALCÃO, B3. Questionário ISE. Net, São Paulo. Seção Sobre. Disponível em: http://mediadrawer.gvces.com.br/ise/original/caderno-apresentacaoquestionario-ise.pdf. Acesso em: 15 out. 2021.

CASAGRANDA, Yasmin Gomes; SAUER, Leandro; PEREIRA, Matheus Wemerson Gomes. A percepção dos administradores sobre sustentabilidade empresarial. Interaçóes (Campo Grande), v. 17, n. 3, p. 487-502, 2016.

COLARES, Ana Carolina Vasconcelos et al. O balanço social como indicativo socioambiental das empresas do Índice de Sustentabilidade Empresarial da BM\&F Bovespa. Revista de Contabilidade do Mestrado em Ciências Contábeis da UERJ, v. 17, p. 83-100, 2012.

DIAS, Denise Oliveira; HENKES, Jairo Afonso; DE FÁTIMA ROSSATO, Ivete. A gestão ambiental como ponte entre a empresa e os stakeholders. Revista Gestáo \& Sustentabilidade Ambiental, v. 9, n. 1, p. 3-22, 2020. 
DONAIRE, Denis. Consideraçóes sobre a influência da variável ambiental na empresa. Revista de Administração de Empresas, v. 34, n. 2, p. 68-77, 1994.

EUGÉNIO, Teresa. Avanços na divulgação de informação social e ambiental pelas empresas e a teoria da legitimidade. Revista Universo Contábil, v. 6, n. 1, p. 102-118, 2010.

FERREIRA NETO, José Venâncio et al. Do Environmental Disasters Impact on the Volume of Socio-Environmental Investment and Disclosure of Brazilian Companies?. In: Advances in Environmental Accounting \& Management: Social and Environmental Accounting in Brazil. Emerald Publishing Limited, 2017.

FERREIRA, Janaína da Silva et al. Informaçóes Financeiras Ambientais: diferença entre o nível de disclosure entre empresas brasileiras. Revista de Educaçáo e Pesquisa em Contabilidade, v. 10, n. 1, p. 5-24, 2016.

FLORES, Francisco Sperotto; GAVRONSKI, Iuri. A influência da sustentabilidade sobre o desempenho exportador no mercado internacional da carne bovina. Revista Ciências Administrativas, v. 22, n. 1, p. 192-224, 2016.

FORBES. Vale é excluída de índice de sustentabilidade da B3. Disponível em: https:// forbes.com.br/last/2019/02/vale-e-excluida-de-indice-de-sustentabilidade-da-b3/, 2019. Acesso em 03 abr. 2020.

GARCIA, Alexandre Sanches; ORSATO, Renato J. Índices de sustentabilidade empresarial: porque participar. XXXVII EnAnpad. Rio de Janeiro/RJ, 2013.

KATO, Cristiano Arns et al. Arquitetura e sustentabilidade: projetar com ciência da energia. Dissertação de Mestrado, Universidade Presbiteriana Mackenzie, São Paulo, SP, Brasil. 2008.

MAÇAMBANNI, Tchiara Aparecida et al. Evidenciação socioambiental: uma análise do Balanço Social de empresas do setor elétrico que atuam nas regióes sul e nordeste do Brasil. Revista de Gestáo Ambiental e Sustentabilidade, v. 2, n. 1, p. 123-142, 2013.

MILANI FILHO, Marco Antonio Figueiredo. Responsabilidade social e investimento social privado: entre o discurso e a evidenciação. Revista Contabilidade \& Finanças, v. 19, n. 47, p. 89-101, 2008.

MOLINA, Márcia Cristina Gomes. Desenvolvimento sustentável: do conceito de desenvolvimento aos indicadores de sustentabilidade. Revista Metropolitana de Governança Corporativa (ISSN 2447-8024), v. 4, n. 1, p. 75-93, 2019. 
MOREIRA, A. Exportação perde força com exigência de sustentabilidade. 2018. Disponível em: https:/valor.globo.com/brasil/coluna/exportacao-perde-forca-comexigencia-de-sustentabilidade.ghtml. Acesso em 01 jun. 2020.

MUSSOI, Alex; VAN BELLEN, Hans Michael. Evidenciação ambiental: uma comparação do nível de evidenciação entre os relatórios de empresas brasileiras. Revista de Contabilidade e Organizaçóes, v. 4, n. 9, p. 55-78, 2010.

NAGANO, Renan Toshi et al. Evolução dos relatórios de sustentabilidade e a necessidade da Obrigatoriedade de sua asseguração por terceiros. In: II Simpósio Internacional de Gestáo de Projetos e I Simpósio Internacional de Inovação e Sustentabilidade, São Paulo, 2013. Anais II SINGEP e I S2IS, 2013.

NUNES, Julyana Goldner et al. Análise das variáveis que influenciam a adesão das empresas ao índice BM\&F Bovespa de sustentabilidade empresarial. Revista Base (Administraçáo e Contabilidade) da UNISINOS, v. 7, n. 4, p. 328-340, 2010.

ORIDE, Karen Sanae; MYSZCZUK, Ana Paula. Gestão empresarial e desenvolvimento sustentável: Análise a partir da carteira ISE da Bolsa de Valores de São Paulo (2011-2015). Revista Brasileira de Planejamento e Desenvolvimento, v. 6, n. 1, p. 40-61, 2017.

PALMA, Eliete Pozzobon et al. Estratégias de Negócios Sustentáveis e Desempenho Exportador: uma análise em empresas do setor de gemas e joias. Revista Brasileira de Gestáo de Negócios, v. 16, n. 50, p. 25-42, 2014.

PAULA, Roberta Manfron de; FERREIRA, Manuel Portugal; QUINTE, Paula da Silva. Aplicação das teorias de internacionalização em pequenas empresas. Revista Pretexto, v. 20, n. 2, p. 32-47, 2019.

PLETSCH, Caroline Sulzbach et al. Perfil da evidenciação ambiental das empresas listadas no índice de sustentabilidade empresarial. Contabilidade Vista \& Revista, v. 25, n. 3, p. 57-77, 2014.

ROCHA, Rafael Toniolo da et al. Gestão Sustentável-Motivadores, Barreiras e Percepção de Micro e Pequenos Empresários. Gestão \& Regionalidade, v. 35, n. 106, 2019.

ROVER, Suliani et al. Divulgação de informações ambientais nas demonstrações contábeis: um estudo exploratório sobre o disclosure das empresas brasileiras pertencentes a setores de alto impacto ambiental. Revista de Contabilidade e Organizaçóes, v. 2, n. 3, p. 53-72, 2008.

SANTOS, Gleberson de Santana dos; SEHNEM, Simone; FREITAS, Marília Santos. Avaliação do nível de sustentabilidade de um curtume gaúcho à luz do sistema de gestão ambiental (SGA). Revista de Gestáo Ambiental e Sustentabilidade, v. 4, n. 2, p. $102-$ $117,2015$. 
SANTOS-CORRÊA, Solange Rodrigues do et al. A Contabilidade Ambiental como Garantia de Responsabilidade Ambiental: o caso do passivo ambiental. Revista Brasileira de Contabilidade, n. 200, p. 36-49, 2013.

COSTA, C. A. G. da (2012). Contabilidade ambiental - Mensuração, Evidenciação e Transparência. São Paulo: Atlas.

SOUZA, Marcos Antonio de; RÁSIA, Kátia Arpino; JACQUES, Flavia Veronica Silva. Evidenciação de informaçóes ambientais pelas empresas integrantes do índice de sustentabilidade empresarial-ISE. Revista de Contabilidade e Controladoria, v. 2, n. 1, p. 51-139, 2010.

SOUZA, Roberto Francisco de et al. A legitimidade do Índice de Sustentabilidade Empresarial (ISE) frente aos demais Índices B3. RACE: Revista de Administraçáo, Contabilidade e Economia, v. 18, n. 3, p. 521-542, 2019.

TELES, Camila Duarte et al. Uma proposta para avaliaçáo da sustentabilidade socioambiental utilizando suporte analítico e gráfico. Production, v. 26, n. 2, p. 417-429, 2016. 